\title{
Riociguat dose titration in patients with chronic thromboembolic pulmonary hypertension (CTEPH) or pulmonary arterial hypertension (PAH)
}

\author{
Hossein A Ghofrani*1, Marius M Hoeper ${ }^{2}$, Gert Hoeffken ${ }^{3}$, Michael Halank ${ }^{3}$, \\ Gerrit Weimann ${ }^{4}$, Friedrich Grimminger ${ }^{1}$ for the study group
}

\author{
Address: ${ }^{1}$ University Hospital Giessen and Marburg, Germany, ${ }^{2}$ Hannover Medical School, Germany, ${ }^{3}$ University Hospital Dresden, Germany and \\ ${ }^{4}$ Bayer HealthCare AG, Germany \\ Email: Hossein A Ghofrani* - ardeschir.ghofrani@innere.med.uni-giessen.de \\ * Corresponding author
}

from 4th International Conference of cGMP Generators, Effectors and Therapeutic Implications

Regensburg, Germany. 19-21 June 2009

Published: II August 2009

BMC Pharmacology 2009, 9(SuppI I):SI4 doi:I0.1186/I47I-22I0-9-SI-SI4

This abstract is available from: http://www.biomedcentral.com/l47/-22I0/9/SI/SI4

(c) 2009 Ghofrani et al; licensee BioMed Central Ltd.

\section{Clinical background}

Despite recent advances, the prognosis for patients with pulmonary hypertension remains poor. Riociguat (BAY 63-2521) is a novel oral stimulator of the nitric oxide (NO) receptor soluble guanylate cyclase, and synergizes with low levels of bioavailable NO. Its safety and efficacy in dose titration were studied in patients with PAH $(\mathrm{n}=$ $33)$ or CTEPH $(n=42)$ in this multicenter open-label uncontrolled phase 2 trial.

\section{Results}

Patients received riociguat tid for 12 weeks. Doses were titrated according to systolic blood pressure (SBP) and tolerability; $37.5 \mathrm{mg} /$ day was generally well tolerated. Hypotension (SBP $<90 \mathrm{mmHg}$ ) occurred in 11 cases, but SBP often normalized without dose alteration $(n=9)$; in 2 cases a reduced dose was well tolerated.

Mean pulmonary arterial pressure (PAP) and pulmonary vascular resistance (PVR) decreased from baseline (PAP, $5.3 \mathrm{mmHg}$; PVR, 253 dyn.s/cm5; $\mathrm{p}<0.0001$ ), and cardiac output increased $(0.88 \mathrm{~L} / \mathrm{min} ; \mathrm{p}<0.0001)$. Slight changes from baseline were seen in mean SBP (124 -> $117 \mathrm{mmHg})$ and heart rate $(77->80 \mathrm{bpm})$. PVR/systemic vascular resistance ratio showed slight pulmonary selectivity $(\mathrm{p}=$ 0.0064). Tei index, systolic PAP and TAPSE showed improvement ( $\mathrm{p}$ 0.0041). Mean 6-minute walking dis- tance (6MWD) increased in patients with PAH $(+73.5 \mathrm{~m}$; $\mathrm{p}<0.0001)$ or CTEPH $(+64.3 \mathrm{~m}$; $\mathrm{p}<0.0001)$, and similar trends were found in 6 bosentan-pretreated patients. Similar increases were seen in patients in WHO functional class (FC) II $(\mathrm{n}=14 ;+80.7 \mathrm{~m})$ and III $(\mathrm{n}=55 ;+62.7 \mathrm{~m})$. Plasma NT-proBNP, dyspnea and FC also improved.

\section{Conclusion}

In summary, riociguat significantly improves pulmonary hemodynamics and exercise capacity from baseline in subjects with PAH or CTEPH and warrants further, controlled clinical study. 